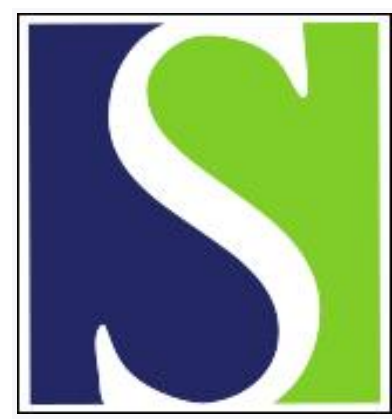

Scand J Work Environ Health 2007;33(2):122-130

https://doi.org/10.5271/sjweh.1115

Issue date: 31 Apr 2007

Consensus-based findings and recommendations for estimating the costs of health-related productivity loss from a company's perspective

by Uegaki K, de Bruijne MC, Anema JR, van der Beek AJ, van Tulder MW, van Mechelen W

Affiliation: EMGO-Institute, VU University Medical Center, Van der Boechorststraat 7, NL-1081 BT, Amsterdam, Netherlands. mc.debruyne@vumc.nl

Refers to the following text of the Journal: 2005;31(5):367-374

The following articles refer to this text: 2007;33(3):161-164; 2008;34(2):120-132; 2009;35(4):301-308; 2009;35(6):403-413; 2010;36(4):313-318

Key terms: absenteeism; company's perspective; consensus; cost; cost estimation; Delphi technique; health-related productivity loss; presenteeism; program evaluation; recommendation

This article in PubMed: www.ncbi.nlm.nih.gov/pubmed/17460800 


\title{
Consensus-based findings and recommendations for estimating the costs of health-related productivity loss from a company's perspective
}

\author{
by Kimi Uegaki, MHS, ${ }^{1,2}$ Martine $C$ de Bruijne, PhD, ${ }^{1,2}$ Johannes $R$ Anema, PhD, ,2, 4 Allard J van der \\ Beek, $P h D,{ }^{2,3}$ Maurits W van Tulder, PhD, 1, 5 Willem van Mechelen, PhD ${ }^{2,3}$
}

\begin{abstract}
Uegaki K, de Bruijne MC, Anema JR, van der Beek AJ, van Tulder MW, van Mechelen W. Consensus-based findings and recommendations for estimating the costs of health-related productivity loss from a company's perspective. Scand J Work Environ Health 2007;33(2):122-130.
\end{abstract}

\begin{abstract}
Objectives There were two study objectives: (i) to identify, via consensus, a key set of items for estimating the costs of productivity loss from a company's perspective and (ii) to develop recommendations for the costs of estimating productivity loss on the basis of consensus findings.

Methods A modified Delphi procedure was utilized in which a predetermined set of 26 items formed the basis for inquiry in the first round. Thirty-six experts from five stakeholder groups in the Netherlands (employers, employees, policy makers and insurers, occupational health professionals, and researchers) participated in the panel. Opinions were sought regarding the relevance and retrievability of data on items related to the following three forms of work loss: work presenteeism (ie, decreased work performance while at work), short-term absenteeism ( $<2$ weeks), and long-term absenteeism ( $>2$ weeks). The data were analyzed quantitatively and qualitatively. The consensus for relevance was set at $70 \%$.

Results After two rounds, 4 items were found relevant for estimating the costs of productivity loss due to work presenteeism, 6 items were relevant for short-term absenteeism, and 11 items remained for long-term absenteeism. The retrievability of data varied. Three sets of recommendations were formulated for estimating the costs of productivity loss from a company's perspective.

Conclusion A streamlined set of relevant items has been identified via consensus and formulated into recommendations for estimating the costs of productivity loss from a company's perspective. Although not definitive, these recommendations represent an important step towards standardizing the way these costs are estimated, and, in turn, facilitate the comparability and utility of economic evaluations of occupational health interventions.
\end{abstract}

Key terms absenteeism, Delphi technique, method, presenteeism, program evaluation.

Research on health outcomes aims at evaluating treatment efficiency and at generating information to support rational decision making with regard to the allocation of finite resources (1). A specific form of inquiry is the economic evaluation, and, while the societal perspective is traditionally recommended as the framework for such evaluations, the use of a more specific stakeholder perspective may be warranted (2-5).
The socioeconomic impact of health-related work incapacity for companies may be significant. In the Netherlands, for instance, companies are obligated to continue to pay $70-100 \%$ of the salary of ill employees during the first 2 years of illness, regardless of workrelatedness. Literature demonstrating the relationship between health and work productivity and the resultant financial burden of illness is also increasing (6-13). As

1 Section of Health Technology Assessment, Institute for Reseaerch in Extramural Medicine, VU University Medical Center, Amsterdam, Netherlands.

2 Department of Public and Occupational Health, Institute for Reseaerch in Extramural Medicine, VU University Medical Center, Amsterdam, Netherlands.

3 Body@Work, Research Center Physical Activity, Work and Health, TNO-VU Medical Center, Amsterdam, Netherlands.

4 Research Center for Insurance Medicine, AMC-UWV-VUmc (Amsterdam Medical Center - Social Security Agency - VU University Medical Center), Amsterdam, Netherlands.

5 Institute of Health Sciences, Faculty of Earth \& Life Sciences, Vrije Universiteit, Amsterdam, Netherlands.

Reprint requests to: Dr MC de Bruijne, EMGO-Institute, VU University Medical Center, Van der Boechorststraat 7, NL-1081 BT, Amsterdam, Netherlands. [mc.debruyne@vumc.nl] 
companies become more aware of the need to pay attention to the health of their employees and look to implement occupational health interventions in the workplace setting, tailored evidence is required for informative health-investment decision making by a company (2, $3,5,14,15)$.

In economic evaluations conducted from a company's perspective, the benefit of occupational health intervention is commonly expressed in terms of changes (or differences) in productivity loss that can be translated into a monetary value (16). However, objective data on productivity are often lacking, and estimates of the costs of productivity loss are often based on the number of days of sick leave $(1,17)$. In the literature, the need to consider work presenteeism (ie, decreased work performance while on the job) as a component of the costs incurred from productivity loss is increasingly being recognized $(8,13,18)$, and several questionnaires have been developed to measure this phenomenon (19-22). Furthermore, other elements have been suggested, such as costs related to hiring and training replacements, spillover effects to co-workers, and mechanisms that reduce or increase overall productivity loss $(2,23-26)$. However, it is not clear as to whether all suggested elements are equally relevant from a company's perspective.

Thus this study has two objectives, to identify, via consensus among stakeholders in the Netherlands, a key set of items for estimating the costs of productivity loss from a company's perspective and to develop recommendations for items to be included in the estimation on the basis of the consensus findings.

\section{Study population and methods}

\section{Study design}

To meet our objectives, we used a modified Delphi procedure. This method was selected as it lends itself to the formation of a collective opinion on a topic spanning a wide range of stakeholders (27). To improve the practical applicability of the research findings, the consensus procedure involved representatives from key stakeholder groups in occupational health $(4,28)$.

To improve the efficiency of the study procedure, the first round was modified from being predominantly qualitative to quantitative, in which a predetermined set of items was presented to the expert panel for rating (14, $27,29)$. The items were identified from published literature, existing guidelines, and productivity measurement tools, as well as from 10 exploratory interviews with human resource personnel, financial advisors, and occupational physicians employed at various size companies. A concept of the first round questionnaire was piloted $(\mathrm{N}=4)$ before the official commencement of the study.

\section{Panel participants}

Using a combination of convenience and purposive sampling, experts from five stakeholder groups in the Netherlands (employers, employees, policy makers and insurers, occupational health professionals, and researchers) were invited to participate in the panel $(27,30)$. Experts were defined as persons who had a minimum of 3 years' experience in occupational health, absenteeism, or work-productivity-related issues. Fifty potential panel members were approached during a 2month recruitment period (June-August 2005), of whom 36 indicated having sufficient expertise and time to participate. These experts were employed in companies of various sizes located in sectors such as industry, construction, finance, transportation and communication, commercial services, public governance, and health care. The "employer" group (28\% of the panel) included department heads, human resource managers, financial managers, and entrepreneurs. "Employees" $(11 \%)$ were union representatives or chairpersons of safety, health, wellness and environment committees of their respective places of employment. Members of the "policy maker and insurer" group (17\%) often held multiple job roles and had experience in areas such as return to work and work disability. The "occupational health professional" group (25\%) included occupational health physicians and nurses, physiotherapists, and ergonomists. In addition to clinical work, some performed management or consultation tasks. "Researchers" (19\%) were active in areas of study such as health economics, ergonomics, occupational health, and work and organizational psychology. Collectively, $75 \%$ of the members had more than 10 years of relevant experience.

\section{Data collection}

The definitive version of the first-round questionnaire was based upon 26 items, which have been arbitrarily grouped into four categories and coded to facilitate reporting (table 1). Of these, 22 items reflected productivity consequences that may arise from health-related reductions in employee production (work) capacity, and four items (W3, CW5, C12, C13) reflected mechanisms with which negative productivity consequences can be buffered or "compensated". The term "compensation mechanisms" is used to refer to these four latter items in the remainder of this paper. A priori, we expected that the relevance and retrievability of data for certain items would differ depending on the type of work loss at hand. Thus experts' opinions were sought regarding the relevance and retrievability of data for each item with respect to the following three forms of work loss: (i) work presenteeism, (ii) short-term absenteeism ( $<2$ weeks), and (iii) long-term absenteeism ( $>2$ weeks). 
Table 1. Categorized and coded list of the 26 items presented to the panel in round 1.

\begin{tabular}{|c|c|c|}
\hline Category & Code & Item \\
\hline \multirow[t]{7}{*}{ Worker } & W1A & $\begin{array}{l}\text { Duration of the period of presenteeism (reduc- } \\
\text { tion in work performance) }\end{array}$ \\
\hline & W2A & Degree of presenteeism \\
\hline & W1B & Duration of the short-term absenteeism period \\
\hline & W2B & $\begin{array}{l}\text { Degree of absenteeism per day during the given } \\
\text { period of short-term absenteeism }\end{array}$ \\
\hline & W1C & Duration of the long-term absenteeism period \\
\hline & W2C & $\begin{array}{l}\text { Degree of absenteeism per day during the given } \\
\text { period of long-term absenteeism }\end{array}$ \\
\hline & W3 & $\begin{array}{l}\text { Worker able to catch up on tasks after recovery } \\
\text { from illness }\end{array}$ \\
\hline \multirow[t]{5}{*}{ Co-workers } & CW1 & $\begin{array}{l}\text { Amount of time during normal workhours that } \\
\text { co-workers provide coverage at the expense of } \\
\text { less urgent activities such as innovation (loss of } \\
\text { innovative capacity) }\end{array}$ \\
\hline & CW2 & $\begin{array}{l}\text { Amount of overtime hours during which co- } \\
\text { workers take over work for an ill worker }\end{array}$ \\
\hline & CW3 & Increased workload or pressure \\
\hline & CW4 & $\begin{array}{l}\text { Decreased productivity of co-workers who are } \\
\text { dependent on the ill employee }\end{array}$ \\
\hline & CW5 & $\begin{array}{l}\text { Work taken over by co-workers (from an ill, less } \\
\text { effective worker) during normal workhours (as a } \\
\text { buffer) }\end{array}$ \\
\hline \multirow[t]{5}{*}{ Administrators } & $\mathrm{A} 1$ & $\begin{array}{l}\text { Time to arrange temporary coverage via internal } \\
\text { help }\end{array}$ \\
\hline & $\mathrm{A} 2$ & $\begin{array}{l}\text { Time to arrange temporary coverage via external } \\
\text { help }\end{array}$ \\
\hline & $\mathrm{A} 3$ & $\begin{array}{l}\text { Time to recruit and hire a permanent } \\
\text { replacement }\end{array}$ \\
\hline & A4 & $\begin{array}{l}\text { Time to orient and train a (permanent) } \\
\text { replacement }\end{array}$ \\
\hline & A5 & $\begin{array}{l}\text { Time spent facilitating the return to work of ill or } \\
\text { injured worker }\end{array}$ \\
\hline \multirow[t]{13}{*}{ Company } & $\mathrm{C} 1$ & $\begin{array}{l}\text { Loss in the form of missed orders and sales, } \\
\text { lost deals and contracts }\end{array}$ \\
\hline & $\mathrm{C} 2$ & $\begin{array}{l}\text { Decrease in efficiency of replacement worker } \\
\text { during the training and orientation phase }\end{array}$ \\
\hline & C3 & $\begin{array}{l}\text { Costs due to decreased quality of product or } \\
\text { service (eg, returns, rejections, claims under } \\
\text { warranty) }\end{array}$ \\
\hline & C4 & $\begin{array}{l}\text { Idle assets such as unused workspace, material, } \\
\text { inventory (overhead) }\end{array}$ \\
\hline & $\mathrm{C5}$ & Salary of the replacement worker \\
\hline & C6 & $\begin{array}{l}\text { Cost of light duties for the worker on a return-to- } \\
\text { work pathway }\end{array}$ \\
\hline & $\mathrm{C} 7$ & $\begin{array}{l}\text { Change in attractiveness of company as potential } \\
\text { employer under potential recruits }\end{array}$ \\
\hline & $\mathrm{C} 8$ & Change in employee satisfaction \\
\hline & $\mathrm{Cg}$ & $\begin{array}{l}\text { Time and money spent to evaluate the workplace } \\
\text { or implement ergonomic intervention }\end{array}$ \\
\hline & $C 10$ & Legal costs \\
\hline & $\mathrm{C} 11$ & Fines or increases in insurance premiums \\
\hline & $\mathrm{C} 12$ & $\begin{array}{l}\text { Superfluous nature of the function within the } \\
\text { company }\end{array}$ \\
\hline & $\mathrm{C} 13$ & Reimbursement of sick leave costs via insurance \\
\hline
\end{tabular}

In round 1, for each of the three forms of work loss, the panel members were asked to rate how relevant they thought a particular productivity consequence was for estimating the costs of productivity loss from a company's perspective, using a 6-point Likert scale anchored by 0 (completely irrelevant) and 5 (definitely relevant). Concurrently, they were asked to rate the ease with which data on these consequences could be retrieved on a 4-point Likert scale $(0=$ impossible or only with undue effort, $1=$ within a week, 2 = within a day, or 3 $=$ with a click of a mouse). Next, the panel members were asked to indicate whether or not a given compensation mechanism may significantly lessen health-related productivity loss and therefore be included when the costs of productivity loss are estimated. Last, because the ratings could be influenced by the type of worker that the panel members had in mind while completing the questionnaire, additional questions were asked to gain insight into these "representative functions". These questions addressed, for example, the ease with which a perfect substitute could be found, the time sensitive nature of the worktasks, and the degree of teamwork (31). Space was provided for explanations, suggestions for additional items, and general feedback.

In round 2, a summary of the first-round findings were reported back to the panel members. Using the same scales as in round 1, the panel members were asked to re-rate the relevance of a reduced set of items. For each repeated item, the following five sources of feedback were provided: a histogram of the first-round ratings, the percentage of panel members who rated the item as relevant, the mean and standard deviation of the rating, the associated comments, and their respective first-round opinion. Again, space was provided for comments.

\section{Data analysis}

In order to determine the consensus, data from both rounds were analyzed both quantitatively and qualitatively. First, the opinions of the panel members were analyzed by the following three steps: (i) inspection of the response distributions of each panel member per stakeholder group, as well as across groups, (ii) inspection of the response distributions per item for bimodality, and (iii) the calculation and (visual) determination of the (change in) collective opinion regarding the relevance and retrievability of the items in terms of (the change in) frequencies, means, and standard deviations $(32,33)$. To determine the relevance-related frequencies, we regrouped the responses for the 22 items reflecting productivity consequences as "not relevant" (ratings of 0-2) and "relevant" (ratings of 3-5). With respect to the retrievability of data, the frequencies for each rating were determined. For the four items concerning the compensation mechanism, an opinion that an item should be included was interpreted as "relevant" and one that indicated an item should not be included as considered "not relevant". Second, the comments accompanying the panel member ratings were analyzed qualitatively by applying coding techniques (open, axial and selective coding) originating from grounded theory (34). 
The following four "rules" were then followed to identify consensus and determine the item set for round 2: (i) if less than $50 \%$ of the panel members rated the item as relevant, then the item was excluded from further consideration, (ii) if $70 \%$ or more of the panel members rated an item to be relevant, then there was consensus that the item was relevant and should be included in the recommendations, (iii) if 50-69\% of the panel members considered the item to be relevant, then the item was eligible for round 2, and (iv) for all of the irrelevant and borderline items (50-55\% and 67-69\%), the associated comments were closely reviewed to see if an exception to rules 1 or 3 should be made.

\section{Results}

\section{Number of Delphi rounds and response rate}

Altogether, two written rounds were required to meet the objectives of the study. The response rate from round 1 to round 2 was $86 \%$ ( $\mathrm{N}=31$ of 36 persons). In round 2 , $100 \%$ of the employees (4 of 4) and researchers (7 of 7) responded. The response rate of the second round was $70 \%$ (7 of 10), $83 \%$ (5 of 6), and 89\% (8 of 9) for the employers, policy makers and insurers, and occupational health professionals, respectively. Two nonrespondents changed jobs, and one was hindered by extenuating circumstances at work. The reasons for the remaining nonresponses are unknown. The collective experience of the respondents remained high in round 2 (ie, $80 \%$ had more than 10 years' experience).

\section{Pattern of responses}

Across both rounds, the opinions not only varied between members of the same stakeholder group, but also across all of the groups. Similarly, the representative functions varied both within and across the groups. On the average, the representative function was characterized as follows: a perfect substitute was more or less easy to find, worktasks were somewhat difficult to postpone, and work was performed more or less in a team situation. There were no cases in which extreme ratings were given for all three characteristics, nor was a consistent pattern detected between the characteristics of the representative function and the relevance ratings.

\section{Relevance}

The relevance findings from rounds 1 and 2 for work presenteeism, short-term absenteeism, and long-term absenteeism are presented in tables 2,3 , and 4 , respectively. All in all, four items were found to be relevant for estimating the costs of productivity loss due to work

Table 2. Consensus findings for estimating the cost of lost productivity due to work presenteeism, reported in terms of the percentage of panel members (PM) rating a given item as "relevant" (score of $3-5$ ) and the respective means and standard deviations (SD).

\begin{tabular}{|c|c|c|c|c|c|c|c|}
\hline \multirow[t]{2}{*}{ Code } & \multirow[t]{2}{*}{ Item } & \multicolumn{3}{|c|}{ Round 1} & \multicolumn{3}{|c|}{ Round 2} \\
\hline & & $\begin{array}{l}\mathrm{PM} \\
(\%)\end{array}$ & Mean & SD & $\begin{array}{l}\text { PM } \\
(\%)\end{array}$ & Mean & SD \\
\hline W1A & Duration of the presenteeism period & $83^{a}$ & 3.56 & 1.32 & .. & .. & .. \\
\hline W2A & Degree of decreased work performance & $83^{\mathrm{a}}$ & 3.66 & 1.30 &.. & .. & .. \\
\hline W3 & Worker able to catch up on tasks after recovery & $53^{b}$ & .. &.. &.. & .. & .. \\
\hline CW1 & Coverage by co-workers during normal workhours at the expense of less urgent activities & $58^{b}$ & 2.83 & 1.34 &.. & .. & .. \\
\hline CW2 & Amount of overtime hours by co-workers & $85^{\mathrm{a}}$ & 3.82 & 1.24 &.. & .. & .. \\
\hline CW3 & Increased workload or pressure on co-workers & $43^{c}$ & 2.31 & 1.45 & .. & .. &.. \\
\hline CW4 & Decreased productivity of co-workers who are dependent on the less effective worker & $64^{d}$ & 2.67 & 1.39 & $55^{\mathrm{e}}$ & 2.45 & 1.21 \\
\hline CW5 & Work taken over by co-workers during normal worktime (as a buffer) & $72^{\mathrm{a}}$ & .. &.. &.. & .. & .. \\
\hline $\mathrm{C} 1$ & Loss in the form of missed orders, sales, lost deals and contracts & $56^{d}$ & 2.78 & 1.69 & $45^{\mathrm{e}}$ & 2.41 & 1.43 \\
\hline C3 & Costs due to decreased quality of product or service & $67^{d}$ & 2.97 & 1.65 & 47 e & 2.60 & 1.43 \\
\hline C7 & Change in attractiveness of company as employer under potential recruits & $29^{c}$ & 1.66 & 1.66 &.. & .. & .. \\
\hline C8 & Change in employee satisfaction & $46^{c}$ & 2.39 & 1.73 & .. & .. & .. \\
\hline C9 & Time and money spent to evaluate the workplace or implement ergonomic modifications & $50^{b}$ & 2.64 & 1.79 & .. & .. & .. \\
\hline C10 & Legal costs & $40^{c}$ & 2.17 & 1.81 &.. & .. & .. \\
\hline C12 & Superfluous nature of the function & $22^{c}$ & .. & .. &.. &.. & .. \\
\hline C13 & Reimbursement of sick leave costs from insurance & $36^{c}$ & .. & .. &.. & .. & .. \\
\hline
\end{tabular}

a Consensus reached ( $\geq 70 \%$ or insight from comments) and included in recommendations.

${ }^{b}$ Borderline item with reason for exclusion as follows: W3-limited applicability, CW1—overlap with another item, C9—item considered a normal obligation.

c Item excluded from further consideration on the basis of identification as "not relevant" and insights from comments.

"Item taken to round 2 for re-voting.

e Item identified as "not relevant" or collective opinion stable across rounds. 
Table 3. Consensus findings for estimating the costs of lost productivity due to short-term absenteeism (<2 weeks), reported in terms of the percentage of the panel members (PM) rating a given item as "relevant" (score of 3-5) and the respective means and standard deviations (SD).

\begin{tabular}{|c|c|c|c|c|c|c|c|}
\hline \multirow[t]{2}{*}{ Code } & \multirow[t]{2}{*}{ Items } & \multicolumn{3}{|c|}{ Round 1} & \multicolumn{3}{|c|}{ Round 2} \\
\hline & & $\begin{array}{l}\text { PM } \\
(\%)\end{array}$ & Mean & SD & $\begin{array}{l}\text { PM } \\
(\%)\end{array}$ & Mean & SD \\
\hline W1B & Duration of short-term absenteeism period & $91^{\text {a }}$ & 4.29 & 0.94 & .. & .. &.. \\
\hline W2B & Degree of absenteeism per day per period & $78^{a}$ & 3.92 & 1.34 & .. & .. & .. \\
\hline W3 & Worker able to catch up on tasks after recovery & $56^{b}$ & .. & .. & $58^{c}$ & .. &.. \\
\hline CW1 & Coverage by co-workers during normal workhours at the expense of less urgent activities & $70^{a}$ & 3.06 & 1.22 & .. & .. &.. \\
\hline CW2 & Amount of overtime hours by co-workers & 89 a & 4.03 & 1.04 & .. & .. &.. \\
\hline CW3 & Increased workload or pressure on co-workers & $44^{d}$ & 2.50 & 1.28 & .. & .. &.. \\
\hline CW4 & Decreased productivity of co-workers who are dependent on the ill employee & $58^{b}$ & 2.69 & 1.28 & $55^{c}$ & 2.58 & 1.18 \\
\hline CW5 & Work taken over by co-workers during normal work hours (as a buffer) & $72^{a}$ & .. & .. & .. & .. &.. \\
\hline A1 & Time to arrange temporary internal help & $49^{d}$ & 2.37 & 1.31 & .. & .. &.. \\
\hline A2 & Time to arrange temporary external help & $46^{d}$ & 2.34 & 1.49 & .. & .. &.. \\
\hline C1 & Loss in the form of missed orders and sales, lost deals and contracts & $50^{e}$ & 2.92 & 1.50 & .. & .. &.. \\
\hline $\mathrm{C} 2$ & Decrease in efficiency of replacement worker during the training or orientation phase & $56^{b}$ & 2.53 & 1.28 & $55^{c}$ & 2.58 & 1.12 \\
\hline C3 & Costs due to decreased quality of product or service & $58^{b}$ & 2.86 & 1.53 & $58^{c}$ & 2.77 & 1.33 \\
\hline C4 & Idle assets (overhead) & $15^{d}$ & 1.33 & 1.05 &.. & ... & .. \\
\hline C5 & Salary of the replacement worker & $72^{\mathrm{a}}$ & 3.42 & 1.54 & .. & .. &.. \\
\hline C7 & Change in attractiveness of company as employer under potential recruits & $36^{d}$ & 1.92 & 1.57 & .. & .. &.. \\
\hline C8 & Change in employee satisfaction & $49^{d}$ & 2.33 & 1.78 & .. & .. &.. \\
\hline C9 & Time and money spent to evaluate the workplace or implement ergonomic modifications & $44^{d}$ & 2.44 & 1.75 & .. & .. &.. \\
\hline C10 & Legal costs & $29^{d}$ & 1.89 & 1.76 & .. & .. &.. \\
\hline C12 & Superfluous nature of the function & $33^{d}$ & .. & .. & .. & .. &.. \\
\hline C13 & Reimbursement of sick leave costs via insurance & $33^{d}$ & .. & .. & .. & .. &.. \\
\hline
\end{tabular}

a Consensus reached ( $\geq 70 \%$ or insight from comments) and included in recommendations.

b Item taken to round 2 for re-voting.

"Item identified as "not relevant" or collective opinion stable across the rounds.

"Item excluded from further consideration on the basis of identification as "not relevant" and insights from comments.

e Borderline item with reason for exclusion as follows: C1-limited applicability.

presenteeism, six were determined for short-term absenteeism, and there were 11 for long-term absenteeism.

\section{Retrievability of data}

With the exception of the worker-level work loss consequences, there was no difference in the pattern of the retrievability ratings between the three forms of work loss. Whereas more than $50 \%$ of the panel indicated that data on the duration and degree of short- and long-term absenteeism could be retrieved within a day or sooner, more than $60 \%$ indicated that retrieving such data for presenteeism was impossible or would require undue effort. Most of the panel was of the opinion that data on the salary costs of replacements were also retrievable within a day or sooner and that data for the following five consequences could be retrieved within a week or sooner: amount of co-worker overtime (CW2), time spent to facilitate the return-to-work process of the ill employee (A5); cost of light duties (C6), time and money spent to evaluate the workplace or implement ergonomic interventions (C9), and legal costs (C10). More than $50 \%$ of the panel considered retrieving data on the remaining consequences to be impossible or to require undue effort.

\section{Themes emerging from the panel's comments}

The following four themes were identified from the panel's comments: (i) impact and directness, (ii) context specificity, (iii) quality management, and (iv) constraints in measurement. Impact and directness addressed the extent to which a given consequence could be a cost driver or the directness of the relationship of the consequence to the decreased production capacity of the ill worker. Such comments were found by worker-level and company-level productivity consequences.

Context specificity encapsulated comments such as "... less of an effect for short-term absenteeism", "in the construction sector...", and "dependent on the type of function ...." These were often paired with items at the co-worker and company levels. Under quality management, comments indicated that many co-worker and company-level items should not be attributed to a worker's health-related reduction in production capacity but to poor managerial and organizational practices and that administrative consequences were simply "part of the job". Comments from these two themes were often repeated in round 2 .

Constraints in measurement embodied challenges to measuring and registering data in practice. Identified 
Table 4. Consensus findings for estimating the costs of lost productivity due to long-term absenteeism ( $>2$ weeks), reported in terms of the percentage of panel members (PM) rating a given item as "relevant" (score of $3-5$ ) and the respective means and standard deviations (SD).

\begin{tabular}{|c|c|c|c|c|c|c|c|}
\hline \multirow[t]{2}{*}{ Code } & \multirow[t]{2}{*}{ Items } & \multicolumn{3}{|c|}{ Round 1} & \multicolumn{3}{|c|}{ Round 2} \\
\hline & & $\begin{array}{l}\text { PM } \\
(\%)\end{array}$ & Mean & SD & $\begin{array}{l}\text { PM } \\
(\%)\end{array}$ & Mean & SD \\
\hline W1C & Duration of long-term absenteeism period & $97^{\text {a }}$ & 4.53 & 0.74 &.. & .. & .. \\
\hline W2C & Degree of absenteeism per day per period & 94 a & 4.36 & 0.87 & .. & .. & .. \\
\hline W3 & Worker able to catch up on tasks after recovery & $22^{b}$ & . & &.. & .. & .. \\
\hline CW1 & Coverage by co-workers during normal workhours at the expense of less urgent activities & $78^{a}$ & 3.42 & 1.18 &.. & .. & .. \\
\hline CW2 & Amount of overtime hours by co-workers & $94^{\text {a }}$ & 4.31 & 1.02 &.. & .. & .. \\
\hline CW3 & Increased workload or pressure on co-workers & $64^{c}$ & 3.00 & 1.35 & $80^{a}$ & 3.20 & 1.27 \\
\hline CW4 & Decreased productivity of co-workers who are dependent on the ill employee & $74^{a}$ & 3.20 & 1.30 &.$\cdot$ & .. & .. \\
\hline CW5 & Work taken over by co-workers during normal workhours (as a buffer) & $56^{c}$ & .. &.$\cdot$ & $65^{d}$ & .. & .. \\
\hline A1 & Time to arrange temporary internal help & $50^{e}$ & 2.65 & 1.41 &.. & .. & .. \\
\hline A2 & Time to arrange temporary external help & $59^{c}$ & 2.79 & 1.55 & $55^{d}$ & 2.65 & 1.45 \\
\hline A3 & Time to recruit and hire a permanent replacement & $53^{e}$ & 2.64 & 1.53 & .. & .. & .. \\
\hline A4 & Time to orient and train a replacement & $67^{c}$ & 3.03 & 1.46 & $65^{d}$ & 3.00 & 1.24 \\
\hline A5 & Time spent facilitating return to work of ill or injured worker & $72^{a}$ & 3.31 & 1.45 &.. & .. &.$\cdot$ \\
\hline C1 & Loss as in missed orders and sales, lost deals and contracts & $63^{c}$ & 3.14 & 1.54 & $68^{d}$ & 3.13 & 1.18 \\
\hline C2 & Decrease in efficiency of replacement worker during the training and orientation phase & $67^{c}$ & 2.83 & 1.13 & $70^{a}$ & 2.77 & 0.86 \\
\hline C3 & Costs due to decreased quality of product or service & $67^{c}$ & 3.31 & 1.49 & $65^{d}$ & 3.19 & 1.40 \\
\hline C4 & Idle assets (overhead) & $32^{b}$ & 2.03 & 1.29 & .. & .. & .. \\
\hline C5 & Salary of the replacement worker & $81^{\mathrm{a}}$ & 3.83 & 1.52 & .. & .. & .. \\
\hline C6 & Cost of light duties as part of a return-to-work pathway & $64^{c}$ & 3.08 & 1.50 & $71^{a}$ & 3.10 & 1.27 \\
\hline C7 & Change in attractiveness of company as employer under potential recruits & $46^{b}$ & 2.17 & 1.60 & .. & .. & .. \\
\hline C8 & Change in employee satisfaction & $55^{\mathrm{e}}$ & 2.48 & 1.72 &.. & .. &.. \\
\hline C9 & Time and money spent to evaluate the workplace or implement ergonomic modifications & $60^{c}$ & 3.09 & 1.74 & $60^{d}$ & 3.10 & 1.60 \\
\hline C10 & Legal costs & $49^{b}$ & 2.66 & 1.75 & .. & .. & .. \\
\hline C11 & Fines or increases in insurance premiums & $63^{c}$ & 3.11 & 1.91 & $63^{d}$ & 3.37 & 1.66 \\
\hline C12 & Superfluous nature of the function & $17^{b}$ & .. & .. & .. & .. & .. \\
\hline C13 & Reimbursement of sick leave costs via insurance & $58^{c}$ & .. & .. & $71^{a}$ & .. &.. \\
\hline
\end{tabular}

a Consensus reached ( $\geq 70 \%$ or insight from comments) and included in recommendations.

"Item excluded from further consideration on the basis of identification as "not relevant" and insights from comments.

c Item taken to round 2 for re-voting.

d Item identified as "not relevant" or the collective opinion was stable across rounds.

e Borderline item with the following reason for exclusion: A1, C8-related to core management tasks; A3-illogical nature.

obstacles included the intangibleness of certain items, the inability to measure the item at the worker level, and limitations in registration (systems). For related items that could be measured, the validity of utilized methods was questioned as follows: "Documenting time is a creative activity. Every worker has a vested interest in documenting sufficient time."

\section{Recommendations}

Based on a synthesis of the consensus findings and an analysis of the comments, three sets of recommendations for estimating the costs of productivity loss from a company's perspective were formulated (table 5). The recommendations consisted of core and optional elements. The core elements were common across the three types of work loss, whereas the optional elements could differ. The items concerning optional elements have been identified by consensus as being relevant; however, their inclusion may depend upon the circumstances, for example, their applicability to a given function or workplace and the extent to which they are cost drivers.

\section{Discussion}

A challenge exists in occupational health concerning how to bridge the gap between the generation of new evidence on the efficiency of occupational health intervention and its implementation at the company level. Part of the solution can be found in standardizing the way the costs of productivity loss, a key outcome, are estimated, thereby facilitating the comparability and utility of evidence for workplace decision makers. In this study, we aimed at identifying a key set of items to be included in estimations of productivity loss costs from a company's perspective by conducting a modified Delphi procedure. On the basis of the consensus findings 
Table 5. Recommendations for the estimation of productivity loss costs from a company's perspective for work presenteeism, short-term absenteeism (<2 weeks), and long-term absenteeism ( $>2$ weeks).

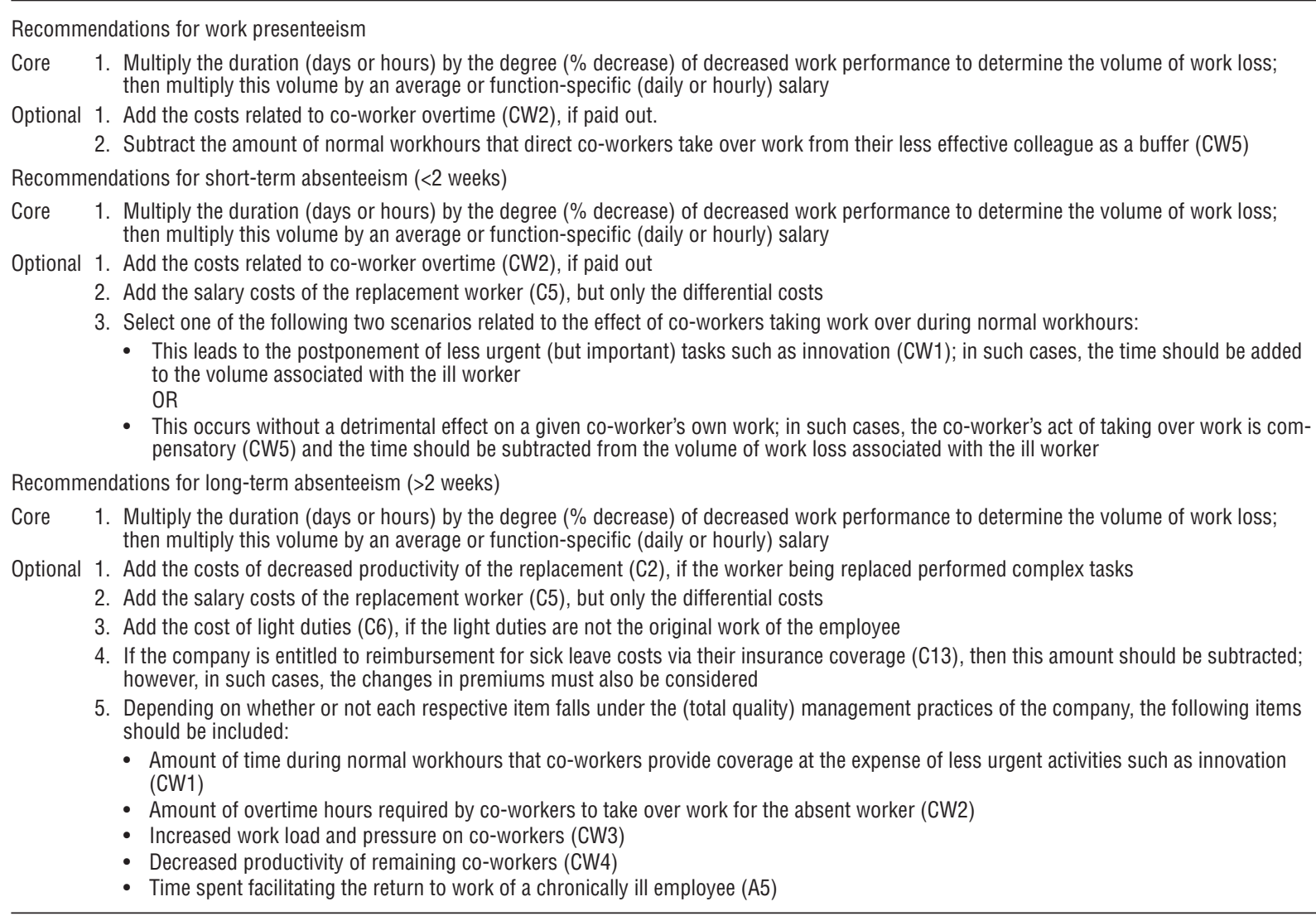

and the panel members' comments, recommendations were formulated.

A primary strength of this study was the involvement of representatives from key occupational health stakeholder groups, as such involvement can improve the practical applicability of research findings $(4,28)$. In addition, the heterogeneous composition improved the likelihood that a wide range of opinions was collected for the formulation of the recommendations.

There were two specific observations that warrant discussion. First, although there are similarities between the three sets of recommendations, there are also differences. This finding confirms our a priori assumption that an item's relevance can be dependent on the type of work loss. While existing questionnaires make a distinction between presenteeism and absenteeism, the differentiation between short-term and long-term absenteeism is lacking. Our findings suggest that not all absenteeism periods are alike in their consequences, and this time component of productivity loss deserves further attention. This finding is in line with new concepts indicating that sick leave and return to work should be seen as an evolving process and multiple phase-specific outcomes should be used (35). Second, with the exception of the duration and degree of short-term and long- term absenteeism and salary costs of replacements, data retrieval in companies may span a week or be regarded as impossible or as requiring undue effort. On a practical level, the recommendations can be used as a checklist to help identify how current data registration (systems) can be improved for the purpose of routine data collection, for instance, by expansion or coupling between databases. With regard to formal economic evaluations, several tools for measuring work productivity have been developed. For an overview, readers should consult the paper by Amick et al (19).

In a modified Delphi study in which six tools for measuring health-related productivity were evaluated, Loeppke et al (21) identified absenteeism, presenteeism, and employee turnover and replacement costs as key elements. Our core items and one optional item are in accordance with these findings. Moreover, the coworker-related optional items point towards the third area of future research that Loeppke et al identified: "3) examination of the impact of an individual's absenteeism and presenteeism on team dynamics and interdependent the workgroups within the work environment [p 358]." (21). In addition, a method for estimating the costs of productivity loss with little direct measurement was recently published (36). In this method, the 
co-worker-related optional items are encapsulated in the so-called "wage multiplier". Furthermore, two questionnaires, the Productivity and Disease Questionnaire (PRODISQ) (20) and Health and Labour Questionnaire (37), which were not included in the study by Loeppke et al, were reviewed to gain insight into the differences between our recommendations and their content. The core items in our recommendations were included in both questionnaires; however, the inclusion of the optional items varied. While our panel did not consider the administrative time needed for planning and arranging replacements to be relevant, often citing that such tasks were fundamental management activities, this item is included in PRODISQ. In addition, there are differences between the items that we identified as compensation mechanisms and what Jacob-Tacken et al (26) and the PRODISQ include (20). Conceptualization of compensation mechanisms, and the interface between what stakeholders identify as relevant, as in our recommendations, and how to measure (via measurement tools) and to value productivity loss warrants future inquiry.

There were three main limitations in this study. First, by foregoing the traditional qualitative first round, we may have inadvertently overlooked an important item. However, given that a pilot was conducted, and panel members were given the opportunity to provide suggestions, such a risk was minimal. Second, while we consider the heterogeneous composition of our panel a strength, it can be argued that this, in fact, is a weakness, as the findings may be less specific. There are two possible assumptions behind this argument. First, different stakeholder groups can have different opinions, and, second, the relevance of a given item may be dependent on a specific context. With respect to the former, however, a similar within-group variation in member response patterns was observed for all of the stakeholder groups. The latter was partially addressed by our a priori assumption and by asking questions about the panel members' representative functions. In addition, the comments on the theme context specificity were carefully considered in the formulation of the recommendations, particularly, the optional ones. Third, the findings are opinions of a single group of Dutch experts and cannot be taken to be reflective of all Dutch experts, nor of experts from different medico-socioeconomic systems. Moreover, the aim of reaching a consensus may have led to a diluted version of the best opinion or the lowest common denominator (32).

So that some insight into this third limitation would be gained, 29 occupational health researchers and professionals from 12 countries (of whom 6 were Dutch researchers who had not participated in our study) were surveyed, following a presentation of the study's results during a recently held (February 2006) international workshop. For items designated as core items in our recommendations for presenteeism, short-term absenteeism, and long-term absenteeism, the average agreement over the number of items by the participants was $100 \%$ $(\mathrm{N}=2)$ in each case. The average participant agreement over the respective optional items was 53\%, 74\%, and $63 \%$. Average participant agreement for the respective excluded items was $70 \%, 70 \%$, and $65 \%$. These observations suggest that the core items are generalizable, but that additional attention should be paid to the potential relevance of the optional and excluded items. The disagreement may be reflective of differences between socioeconomic systems, industrial sectors, or companies themselves. Nevertheless, although both the generalizability and authority of the recommendations may be limited, we believe that this streamlined set of items provides a basis for standardizing the estimation of costs of productivity loss from a company's perspective.

In conclusion, on the basis of the collective opinion of stakeholder representatives, recommendations for estimating the costs of productivity loss from a company's perspective have been formulated for the following three forms of work loss: presenteeism, shortterm absenteeism, and long-term absenteeism. Additional efforts to improve current methodology should be made in collaboration with stakeholders. Although the recommendations may not be considered definitive, they represent an important step towards standardizing estimates of productivity loss costs from a company's perspective, thereby facilitating the comparability and utility of economic evaluations of occupational health interventions.

\section{Acknowledgments}

The authors gratefully acknowledge the members of the expert panel for participating in this study.

The authors extend their gratitude to the Dutch Ministry of Social Affairs and Employment for financial support for this study.

\section{References}

1. Drummond MF, Sculpher MJ, Torrance GW, O’Brien BJ, Stoddart GL. Methods for the economic evaluation of health care programmes. 3rd ed. Oxford: Oxford University Press; 2005.

2. Gustafson DH, Helstad CP, Hung CF, Nelson G, Batalden P. The total costs of illness: a metric for health care reform. Hosp Health Serv Adm. 1995;40(1):154-71.

3. Berger ML, Murray JF, Xu J, Pauly M. Alternative valuations of work loss and productivity. J Occup Environ Med. 2001;43(1):18-24.

4. Young AE, Wasiak R, Roessler RT, McPherson KM, Anema 
JR, van Poppel MN. Return-to-work outcomes following work disability: stakeholder motivations, interests and concerns. J Occup Rehabil. 2005;15(4):543-56.

5. Tompa E, Dolinschi R, de Oliveira C. Practice and potential of economic evaluation of workplace-based interventions for occupational health and safety. J Occup Rehabil. 2006;16(3):367-92.

6. Birnbaum HG, Berger WE, Greenberg PE, Holland M, Auerbach R, Atkins KM, et al. Direct and indirect costs of asthma to an employer. J Allergy Clin Immunol. 2002;109(2):264-70.

7. Bramley TJ, Lerner D, Sames M. Productivity losses related to the common cold. J Occup Environ Med. 2002;44(9):822-9.

8. Lerner D, Amick BC III, Lee JC, Rooney T, Rogers WH, Chang H, et al. Relationship of employee-reported work limitations to work productivity. Med Care. 2003;41(5):649-59.

9. Boles M, Pelletier B, Lynch W. The relationship between health risks and work productivity. J Occup Environ Med. 2004;46(7):737-45.

10. Goetzel RZ, Long SR, Ozminkowski RJ, Hawkins K, Wang S, Lynch W. Health, absence, disability, and presenteeism cost estimates of certain physical and mental health conditions affecting U.S. employers. J Occup Environ Med. 2004;46(4):398-412.

11. Keyes CL, Grzywacz JG. Health as a complete state: the added value in work performance and healthcare costs. J Occup Environ Med. 2005;47(5):523-32.

12. Lötters F, Meerding W-J, Burdorf A. Reduced productivity after sickness absence due to musculoskeletal disorders and its relation to health outcomes. Scand J Work Environ Health. 2005;31(5):367-74.

13. Meerding WJ, Ijzelenberg W, Koopmanschap MA, Severens JL, Burdorf A. Health problems lead to considerable productivity loss at work among workers with high physical load jobs. J Clin Epidemiol. 2005;58(5):517-23.

14. van der Beek AJ, Frings-Dresen MH, van Dijk FJ, Houtman IL. Priorities in occupational health research: a Delphi study in The Netherlands. Occup Environ Med. 1997;54(7):504-10.

15. Mayne TJ, Howard K, Brandt-Rauf PW. Measuring and evaluating the effects of disease on workplace productivity. J Occup Environ Med. 2004;46(6 Suppl):S1-S2.

16. Greenberg PE, Birnbaum HG, Kessler RC, Morgan M, Stang P. Impact of illness and its treatment on workplace costs: regulatory and measurement issues. J Occup Environ Med. 2001;43(1):56-63.

17. Miller P, Rossiter P, Nuttall D. Demonstrating the economic value of occupational health services. Occup Med (Lond). 2002;52(8):477-83.

18. Brouwer WB, van Exel NJ, Koopmanschap MA, Rutten FF. Productivity costs before and after absence from work: as important as common? Health Policy. 2002;61(2):173-87.

19. Amick BC III, Lerner D, Rogers WH, Rooney T, Katz JN. A review of health-related work outcome measures and their uses, and recommended measures. Spine. 2000;25(24):3152-60.

20. Koopmanschap MA. PRODISQ: a modular questionnaire on productivity and disease for economic evaluation studies. Expert Rev Pharmacoecon Outcomes Res. 2005;5(1):23-8.

21. Loeppke R, Hymel PA, Lofland JH, Pizzi LT, Konicki DL, Anstadt GW, et al. Health-related workplace productivity measurement: general and migraine-specific recommendations from the ACOEM Expert Panel. J Occup Environ Med. 2003;45(4):349-59.

22. Kessler RC, Barber C, Beck A, Berglund P, Cleary PD, McKenas D, et al. The World Health Organization Health and Work Performance Questionnaire (HPQ). J Occup Environ Med. 2003;45(2):156-74.

23. Boden LI, Biddle EA, Spieler EA. Social and economic impacts of workplace illness and injury: current and future directions for research. Am J Ind Med. 2001;40(4):398-402.

24. Berger ML, Howell R, Nicholson S, Sharda C. Investing in healthy human capital. J Occup Environ Med. 2003;45(12):1213-25.

25. Gerth WC, Sarma S, Hu XH, Silberstein SD. Productivity cost benefit to employers of treating migraine with rizatriptan: a specific worksite analysis and model. J Occup Environ Med. 2004;46(1):48-54.

26. Jacob-Tacken KHM, Koopmanschap MA, Jan Meerding W, Severens JL. Correcting for compensating mechanisms related to productivity costs in economic evaluations of health care programmes. Health Econ. 2005;14(5):435-43.

27. Hasson F, Keeney S, McKenna H. Research guidelines for the Delphi survey technique. J Adv Nurs. 2000;32(4):1008-15.

28. Hoffmann C, Graf von der Schulenburg JM. The influence of economic evaluation studies on decision making: a European survey. Health Policy. 2000;52(3):179-92.

29. Evers S, Goossens M, de Vet H, van Tulder M, Ament A. Criteria list for assessment of methodological quality of economic evaluations: consensus on health economic criteria. Int J Technol Assess Health Care. 2005;21(2):240-5.

30. Domholdt E. Selection and assignment of subjects: physical therapy research: principles and applications. Philadelphia (PA): WB Saunders Co; 1993. p 105-20.

31. Pauly MV, Nicholson S, Xu J, Polsky D, Danzon PM, Murray $\mathrm{JF}$, et al. A general model of the impact of absenteeism on employers and employees. Health Econ. 2002;11(3):221-31.

32. Powell C. The Delphi technique: myths and realities. J Adv Nurs. 2003;41(4):376-82.

33. Greatorex J, Dexter T. An accessible analytical approach for investigating what happens between the rounds of a Delphi study. J Adv Nurs. 2000;32(4):1016-24.

34. Boeije H. Methoden en technieken van kwalitatieve analyse. Analyseren in kwalitatief onderzoek: Denken en doen [Methods and techniques of qualitative analysis: qualitative research analysis: concepts and application]. Amsterdam: Boom Onderwijs; 2005. p 84-120.

35. Young AE, Roessler RT, Wasiak R, McPherson KM, van Poppel MN, Anema JR. A developmental conceptualization of return to work. J Occup Rehabil. 2005;15(4):557-68.

36. Nicholson S, Pauly MV, Polsky D, Sharda C, Szrek H, Berger ML. Measuring the effects of work loss on productivity with team production. Health Econ. 2006;15(2):111-23.

37. van Roijen L, Essink-Bot ML, Koopmanschap MA, Bonsel G, Rutten FF. Labor and health status in economic evaluation of health care: The Health and Labor Questionnaire. Int J Technol Assess Health Care. 1996;12(3):405-15.

Received for publication: 12 May 2006 